\title{
Oral contraceptives and rheumatoid arthritis: new data from the Royal College of General Practitioners' oral contraception study
}

\author{
Philip C Hannaford, Clifford R Kay, Sybil Hirsch
}

\begin{abstract}
From data available at April 1987 it was found that the standardised risk ratio for rheumatoid arthritis between current users of oral contraceptives and never users was $0.82(95 \%$ confidence interval 0.59 to 1.15 ); the ratio between former users and never users was 0.94 (95\% confidence interval 0.72 to 1.22$)$. Important secular trends have occurred within our study population. The incidence of rheumatoid arthritis among former and never users has declined over the past two decades. Current users have not experienced this temporal trend, and the ratio between current and never users has, therefore, approached unity. These secular changes may explain why some studies have found that oral contraceptives have a protective effect, while others have been unable to show such an effect.
\end{abstract}

There is still controversy about whether the use of oral contraceptives is associated with a reduced risk of developing rheumatoid arthritis. ${ }^{1}$ In 1978 the Royal College of General Practitioners reported a halving of risk in current pill users. ${ }^{2}$ Three Dutch studies have subsequently found a reduced risk among women who have ever used the pill..$^{3-5}$ A Swedish study found a significant reduction in past users, ${ }^{6}$ and another British study also found a reduced risk among ever-users. ${ }^{7}$ Other workers have not been able to show any reduction in risk. ${ }^{8-12}$ We report our latest findings, which are based on data available at April 1987.

\section{Methods \\ A detailed description of the study design, the potential biases, and the principles underlying the interpretation of the data has been published elsewhere. ${ }^{13}$ During a 14 month period, which started in May 1968, 1400 general practitioners throughout the United Kingdom recruited 23000 women who were using oral contra- ceptives and a similar number who had never used oral contraceptives (controls). The two groups were matched for age and all subjects were married, or living as married. At six- monthly intervals since recruitment the general practitioner has supplied for each woman still in the study details of any oral contraceptives prescribed and all newly presenting episodes of illness.}

During the course of the study three main oral contraceptive user groups have evolved: current user, former user, and never user. Each woman's contraceptive status can change and, therefore, she might have contributed periods of observation to each of the three comparison groups. For each calendar month in which a subject uses an oral contraceptive one month is added to the period of exposure of current users. If that women stops using the pill her subsequent periods of observation are included in the former user group, unless she restarts use, in which case she again contributes from the date of change to the current users' periods of observation. Controls are those women who have never used the pill. If a woman is recruited as a control but starts to use the pill, her subsequent experience, as long as oral contraceptive use continues, is included in the current user group.

These analyses are based on women who had their first diagnosis of rheumatoid arthritis (International Classification of Diseases 8th revision, 712.3) during the study. Diagnostic criteria were not specified in the study protocol. In our previous paper ${ }^{2}$ we mounted an additional investigation to determine whether the doctors applied different criteria to the three comparison groups. There was no evidence that this was the case, and the difference in incidence between users and never users was not materially influenced by the rigour of the diagnostic criteria applied. Women known to suffer from the disease at recruitment were excluded, as were events and periods of observation related to pregnancy. Each case was categorised according to the woman's contraceptive status at the time of the event. The rates were indirectly standardised for age and parity at the time of the event and smoking history and social class at recruitment, using the entire study cohort as the reference population. The $95 \%$ confidence intervals for the risk ratios were derived from the assumption that the standard deviation of the $\log$ relative risk is equal to the sum of the reciprocals of the observed number of cases in the two groups being compared. Tests for linear trends are based on Mantel's method ${ }^{14}$ modified to accommodate standardised data.

\section{Results}

Table 1 shows the rates of rheumatoid arthritis reported for each contraceptive group by age at diagnosis. For all ages current and former users had similar rates to that of the never users 
Table 1 Standardised rheumatoid arthritis rates in each contraceptive group by age at diagnosist

\begin{tabular}{|c|c|c|c|c|c|}
\hline \multirow[t]{2}{*}{ Age at diagnosis } & \multicolumn{3}{|c|}{ Standardised rates per $T W Y \ddagger(n)$} & \multicolumn{2}{|c|}{ Risk ratios (95\% confidence interval) } \\
\hline & $\begin{array}{l}\text { Current } \\
\text { users }\end{array}$ & $\begin{array}{l}\text { Former } \\
\text { users }\end{array}$ & $\begin{array}{l}\text { Never } \\
\text { users }\end{array}$ & $\begin{array}{l}\text { Current users/ } \\
\text { never users }\end{array}$ & $\begin{array}{l}\text { Former users/ } \\
\text { never users }\end{array}$ \\
\hline $\begin{array}{l}<24 \\
25-29 \\
30-34 \\
35-39 \\
40-44 \\
45-49 \\
50-54 \\
55+\end{array}$ & $\begin{array}{l}0.00 \\
0.21(5) \\
0.79(22) \\
0.55(12) \\
0.22(3) \\
0.55(3) \\
3.14(2) \\
0.00\end{array}$ & $\begin{array}{l}0.57(2) \\
0.15(2) \\
0.61(16) \\
0.49(18) \\
0.93(31) \\
0.78(19) \\
0.87(12) \\
0.68(4)\end{array}$ & $\begin{array}{l}0.63(5) \\
0.53(12) \\
0.43(14) \\
0.50(19) \\
0.75(26) \\
0.94(23) \\
1.32(17) \\
1.46(9)\end{array}$ & $\begin{array}{l}0.00 \\
0.40(0.14-1.14) \\
1.84(0.94-3.60) \\
1.10(0.53-2.27) \\
0.29(0.09-0.96)^{*} \\
0.59(0.18-1.97) \\
2.38(0.55-10.30) \\
0.00\end{array}$ & $\begin{array}{l}0.90(0.17-4.64) \\
0.28(0.06-1.25) \\
1.42(0.69-2.91) \\
0.98(0.51-1.87) \\
1.24(0.74-2.09) \\
0.83(0.45-1.52) \\
0.66(0.32-1.38) \\
0.47(0.14-1.53)\end{array}$ \\
\hline $\begin{array}{l}\text { All women } \\
\text { Period of observation (woman-years) }\end{array}$ & $\begin{array}{l}0.54(47) \\
105412\end{array}$ & $\begin{array}{l}0.62(104) \\
154480\end{array}$ & $\begin{array}{l}0.66(125) \\
181475\end{array}$ & $0.82(0.59-1 \cdot 15)$ & $0.94(0 \cdot 72-1 \cdot 22)$ \\
\hline
\end{tabular}

${ }^{*} \mathrm{p}<0.05$.

Indirectly standardised for parity at diagnosis, social class, and smoking at recruitment.

$\ddagger T W Y=$ thousand woman-years.

Table 2 Standardised rheumatoid arthritis rates in each contraceptive group, observed in different time periodst

\begin{tabular}{|c|c|c|c|c|c|}
\hline \multirow[t]{2}{*}{ Observation period } & \multicolumn{3}{|c|}{ Standardised rates per $T W Y \ddagger(n)$} & \multicolumn{2}{|c|}{ Risk ratios ( $95 \%$ confidence interval) } \\
\hline & Current users & Former users & Never users & $\begin{array}{l}\text { Current users/ } \\
\text { never users }\end{array}$ & $\begin{array}{l}\text { Former users/ } \\
\text { never users }\end{array}$ \\
\hline $\begin{array}{l}\text { May } 1968 \text { to August } 1974 \\
\text { September } 1974 \text { to December } 1980 \\
\text { January } 1981 \text { to April } 1987\end{array}$ & $\begin{array}{l}0.49(27) \\
0.62(17) \\
0.73(3)\end{array}$ & $\begin{array}{l}0.83(24) \\
0.75(50) \\
0.42(30)\end{array}$ & $\begin{array}{l}0.99(68) \\
0.43(28) \\
0.53(29)\end{array}$ & $\begin{array}{l}0.49(0.31-0.77)^{* *} \\
1.44(0.79-2.63) \\
1.38(0.42-4.53)\end{array}$ & $\begin{array}{l}0.84(0.53-1.34) \\
1.74(1.10-2.76)^{*} \\
0.79(0.47-1.32)\end{array}$ \\
\hline Trend test $\left(\chi^{2}\right)$ & 0.85 & $7 \cdot 52^{* *}$ & $10 \cdot 89^{* *}$ & & \\
\hline
\end{tabular}

${ }^{*} \mathrm{p}<0.05 .{ }^{* *} \mathrm{p}<0.01$.

Indirectly standardised for age and parity at diagnosis, social class, and smoking at recruitment.

$\ddagger T W Y=$ thousand woman-years.

(relative risk 0.82 and 0.94 respectively). Among the former and never users there was a significant trend of increasing rates with age $\left(\chi^{2}=5 \cdot 7, p<0.02\right.$ and $\chi^{2}=15.0, p<0.01$ respectively). There was no such trend among the current users $\left(\chi^{2}=0.85, \mathrm{p}>0.05\right)$. Although users who were aged 40 to 44 years at diagnosis had a significantly lower risk of rheumatoid arthritis than similarly aged never users (relative risk $0 \cdot 29$ ), none of the risk ratios specific to other ages was statistically significant.

Parity, smoking, social class, duration of oral contraceptive use, and oestrogen or progestogen content of brands used did not affect the rheumatoid arthritis rates.

Table 2 reports the secular trends for the years 1968 to 1987 . There has been a significant decline in the incidence of rheumatoid arthritis among former and never users but not among current users. These secular changes had an important effect on the risk ratios between pill users and never users. From May 1968 to August 1974 the ratio between current users and never users was significantly reduced $(0 \cdot 49)$, while that between former users and never users was $0 \cdot 84$. These results were derived from essentially the same data as those reported in 1978. ${ }^{2}$ From September 1974 to December 1980 the ratio between current and never users was 1.44 and that between former and never users was significantly increased to $1 \cdot 74$. The corresponding ratios between January 1981 and April 1987 were 1.38 and 0.79 respectively.

\section{Discussion}

In contrast with our previous finding of a $50 \%$ reduction in incidence, ${ }^{2}$ the present evidence is that women who were using the pill at the time of diagnosis had a statistically non-significant
$20 \%$ reduction in their risk of rheumatoid arthritis. This change is probably a reflection of important secular changes in disease incidence which have occurred within our study population.

Potential biases must be considered. Nearly $65 \%$ of the study subjects have been lost to follow up, mainly because the women have moved away from the practice area of the recruiting doctor. Compared with those still under observation, these women tend to be younger, of lower parity, and higher social class, but have similar smoking habits. Everusers who have been lost to follow up, however, have very similar characteristics to those never users who have ceased to remain under observation. Thus the relative incidence between users and non-users is unlikely to have been biased. Apparent negative secular trends would be produced if those women no longer under observation were more prone to developing rheumatoid arthritis than those remaining under observation. We would expect, however, to find the negative temporal trends in current users as well as former users and never users. This suggests that the observed trends are not due to bias. Further, decreasing trends in rheumatoid arthritis rates have been observed in other populations. In America, female residents of Rochester had a $50 \%$ reduction in incidence over a 10 year period starting in the mid1960s. ${ }^{15}$ In Britain, the incidence reported during the Third National Morbidity Survey, conducted in 1981-82, was $20 \%$ lower than that reported during the second survey completed 10 years earlier. ${ }^{16}$ In addition, the incidence of rheumatoid arthritis recorded between 1980 and 1985 by the weekly returns service of the Royal College of General Practitioners has shown a $50 \%$ decrease. ${ }^{17}$ 
Changes in ascertainment or diagnostic bais might produce secular trends. We have previously shown ${ }^{2}$ that the relative frequency of reporting between contraceptive groups remained materially unaffected by the diagnostic method applied. Although we have not specifically compared the diagnostic criteria used at different times, it seems unlikely that with respect to rheumatoid arthritis there have been important changes over the past 19 years.

Our findings suggest that there is an association between the use of oral contraceptives and rheumatoid arthritis. There was no evidence of an increasing rate specific for age among current users (table 1) and early in the study current users had a significant $50 \%$ risk reduction (table 2). It is difficult to explain why we have not observed a secular trend among our current users. Perhaps, having already benefited from a reduced incidence associated with pill use, the current users had already reached an irreducible threshold and were unable to benefit further from those factors associated with a decrease in the rate of rheumatoid arthritis in the general population. In effect, changes in population incidence are obscuring the protective effect of oral contraceptives. Such an explanation might account for the conflicting results from other studies. Vandenbroucke et al have shown that nearly all of the European studies point towards a protective effect, while all of the risk estimates from the American studies are closely clustered around unity. ${ }^{1}$ The discrepancy might be explained if American women experienced a decline in the incidence of rheumatoid arthritis at a different time than European women.

The statistically significant increased ratio between former users and never users observed between September 1974 and December 1980 (table 2) was probably a chance finding. Former users experienced a gradual temporal decline in incidence rates, whereas never users experienced a dip during the second time period. This produced, for the same time period, an increased risk ratio, which was inconsistent with the decreased ratios observed in the earlier and later periods.

It has been argued that a selection bias might have occurred at the time of recruitment. ${ }^{18}$ The argument depended upon the possibility that pill use actually increased the early manifestations of rheumatoid arthritis, and such women who developed joint symptoms would have stopped the pill before the study began and would thus have become ineligible for recruitment as current users or never users. Thus the $80 \%$ of current users recruited who had pill exposure beforehand might have been those women who had a lower likelihood of subsequent rheumatoid arthritis. In fact there was no evidence for such a bias. The rheumatoid arthritis rate among those women who had used the pill for the first time after recruitment $(0.44$ per thousand woman-years) was not significantly different from that occurring in women who had some use before recruitment (0.67 per thousand woman-years).

In the Oxford/Family Planning Association contraceptive study there was a strong association between rheumatoid arthritis and smoking. ${ }^{10}$
We have been unable to find a similar correlation. The evidence for an association between parity and rheumatoid arthritis is conflicting. Nulliparous women had an increased risk of rheumatoid arthritis in one case control study, ${ }^{7}$ though other epidemiological data support the hypothesis that nulliparity may be protective, at least for seropositive disease. ${ }^{19}$ Within our data we could not find a relation between rheumatoid arthritis and parity.

In conclusion, there is evidence that the incidence of rheumatoid arthritis among former and never users, and in the general population, has declined over the past two decades. The magnitude of the decrease is similar to that associated with current use of oral contraceptives. Current users have not experienced this temporal trend, and the ratio between current and never users has, therefore, approached unity. These secular changes may explain the discrepancies between studies conducted on either side of the Atlantic.

We thank the 1400 general practitioners who contributed data for this survey and Mrs Mavis Drabble for her patient preparation of the manuscript. The study was supported by a major grant from the Medical Research Council. The costs of current supplementary expenditure have been met by financial support from Schering Health Care, G D Searle and Co, Syntex Pharmaceuticals, and John Wyeth and Brother.

1 Vandenbroucke J P, Hazes J M W, Dijkmans B A C, Cats A Oral contraceptives and the risk of rheumatoid arthritis: The great transatlantic divide? Br $\mathcal{F}$ Rheumatol 1989; 28 (suppl 1): 1-3.

2 Royal College of General Practitioners' Oral Contraception Study. Reduction in incidence of rheumatoid arthritis associated with oral contraceptives. Lancet 1978; i: 569-71.

3 Vandenbroucke J P, Valkenburg H A, Boersma J W, et al. Oral contraceptives and rheumatoid arthritis: furthe evidence for a preventive effect. Lancet 1982; ii: 839-42.

4 Vandenbroucke J P, Witteman J C M, Valkenburg H A, et al. Noncontraceptive hormones and rheumatoid arthritis in perimenopausal women. $¥ A M A$ 1986; 255: 1299-303.

5 Hazes M, Dijkmans B A C, Vandenbroucke J P, De Vries R R P, Cats A. The preventive effect of oral contraceptives on the incidence of rheumatoid arthritis. Clin Exp Rheumatol 1987; 5 (suppl 2): 27.

6 Allebeck P, Ahlbom A, Ljungstrom K, Allander E. Do oral contraceptives reduce the incidence of rheumatoid arthritis? Scand F Rheumatol 1984; 13: 140-6.

7 Spector T, Silman A, Roman E. Protective effect of prior ora contraceptive use for rheumatoid arthritis. Arthritis Rheum 1988; 31: S581.

8 Linos A, Worthington J W, O'Fallon W M, Kurland L T. Case-control study of rheumatoid arthritis and prior use of oral contraceptives. Lancet 1983; i: 1299-300.

9 Liang M H, Stoker V, Larson M, Willett W, Speizer F, Hennekens C. Oestrogen use, menopausal status and relationship to rheumatoid arthritis. Ann Rheum Dis 1984; relationship $115-6$.

10 Del Junco D J, Annegers J F, Luthra H S, Coulam C B Kurland $L T$. Do oral contraceptives prevent rheumatoid arthritis? $\mathcal{F} A M A$ 1985; 254: 1938-41.

11 Vessey M P, Villard-Mackintosh L, Yeates D. Oral contraceptives, cigarette smoking and other factors in relation to arthritis. Contraception 1987; 35: 457-64.

12 Hernandez-Avila $M$, Liang $M$, Willett W C, et al. Ora contraceptives and postmenopausal hormone use and the risk of rheumatoid arthritis. Arthritis Rheum 1988; 31: S36.

13 Royal College of General Practitioners. Oral contraceptives and health. London: Pitman Medical, 1974.

14 Mantel, N. Chi-squared test with one degree of freedom. Extension of the Mantel-Haenszel procedure. American Extension of the Mantel-Haenszel
Statistical Association 1963; 58: 690 .

15 Linos A, Worthington J W, O'Fallon M, Kurland L T. The epidemiology of rheumatoid arthritis in Rochester, Minnesota: a study of incidence, prevalence, and mortality. Am nesota: a study of incidence, pre

16 Hochberg M C. Contrasting trends in the incidence and prevalence of rheumatoid arthritis (RA) in England and Wales, 1970-1982. Arthritis Rheum 1988; 31 (suppl 1): R34. 17 Silman A J. Recent trends in rheumatoid arthritis. Br $\mathcal{J}$ Rheumatol 1986; 25: 328-30.

18 Esdaile J M, Horwitz R I. Observational studies of causeeffect relationships: an analysis of methodologic problems as illustrated by the conflicting data for the role of ora contraceptives in the etiology of rheumatoid arthritis. $\checkmark$ Chronic Dis 1986; 39: 841-52.

19 Silman A J. Is pregnancy a risk factor in the causation of rheumatoid arthritis? Ann Rheum Dis 1986; 45: 1031-4. 